\title{
Research on the Examination Mode of Blending Teaching based on National Learning Resources Repository On Computing Application Technology
}

\author{
--Case Study of Virtual Technology
}

\author{
Haiyan Liu \\ Department of Computer and communication Engineering \\ Beijing Information Technology College \\ Beijing, China \\ lhy li@sina.com
}

\author{
Xiaomin Liu \\ Water Conservancy and Civil Engineering College of Inner \\ Mongolia Agricultural University, Inner Mongolia \\ Inner Mongolia, China
}

\author{
Qi Sun \\ Department of Computer and communication Engineering \\ Beijing Information Technology College \\ Beijing, China
}

\begin{abstract}
A multi-angle student examination mode combined with the characteristics of the computer courses is presented on the basis of the existing examination methods in order to overcome the shortcomings of examination mode of the blending teaching. The mode integrates the online examination and the offline examination effectively. Firstly, the paper summarizes the existing problems of the examination mode of the blending teaching. Secondly, the framework of examination mode is presented and describes the content of every layer in detail. Lastly, the mode is applied to the virtualization technology Course. The experimental results show that the examination mode is very effective and can reflect objectively the student's learning situation.
\end{abstract}

Keywords-Blending Teaching; Higher Vocational Education; Examination Mode; Virtual Technology

\section{INTRODUCTION}

Blending Teaching combines the advantages of the traditional teaching methods with the advantages of the networked teaching methods. It plays a leading role in guiding, inspiring and monitoring the teaching process, and fully embodies the initiative, enthusiasm and creative of the students as the main body of the learning process [1-3]. And then blending teaching can improve the quality of teaching and can improve students' independent thinking, innovation and comprehensive competitive ability. At present, the blending teaching mainly focuses on definition, mode, strategy and principle. The study of blending teaching is less on the teaching practice, and learning effect [4-6]. The whole system and operation method have not been formed yet. The purpose of some examination modes of blending teaching is still to improve student achievement and ignores the students' usual performance. These can't give full play to the advantages of the blending teaching.
In order to solve the above problems, the paper uses the resources provided by National Learning Resources Repository to integrate the online examination and the offline examination effectively, to design a multi-angle student examination mode, and to apply it to the virtualization technology Course.

\section{THE DESIGN OF EXAMINATION MODE OF BLENDING TEACHING}

The traditional course examination mode focuses on the summative evaluation of students' final examination and the blending teaching needs to consider various teaching methods used in the process to teaching to construct a comprehensive, scientific, objective and accurate assessment evaluation system, to stimulate students' interesting in learning and enthusiasm.

The paper combines with the characteristics of blending teaching and the basic situation of students and integrates the formative evaluation and the summative evaluation to study the comprehensive learning situation of students and to test the effect of blending teaching. The examination method is shown in Fig. 1. Among them, the formative evaluation is mainly composed of e-learning and offline learning, the summative evaluation includes mid-term examination and final examination. The following sections describe them in detail. 


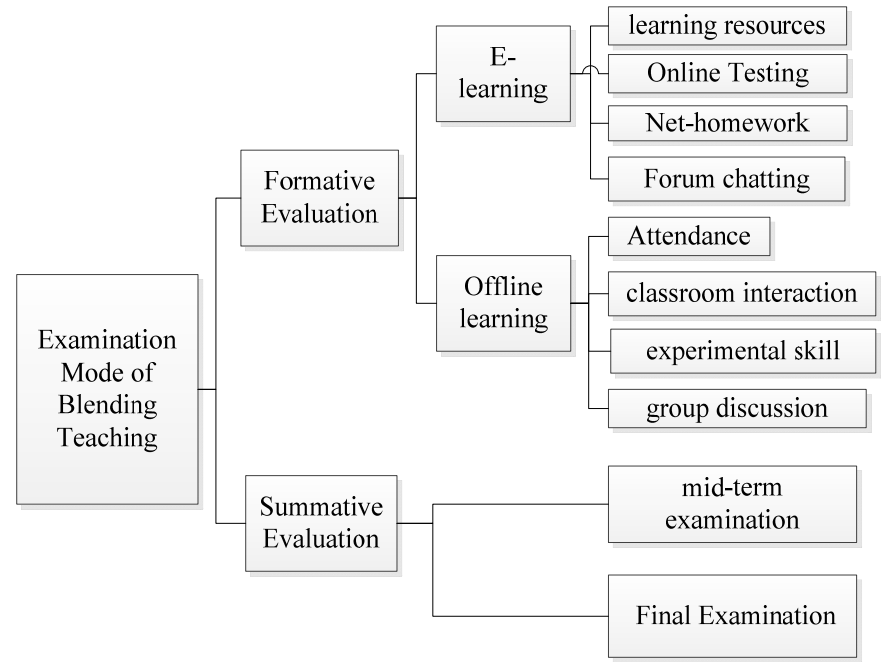

Fig. 1. The Examination Mode of Blending Teaching Diagram

\section{A. E-learning}

E-learning includes mainly learning resources, online testing, Net-homework and forum chatting. Learning resources include course guide, classroom teaching, reflecting emphasis and difficulty of micro-class and library sharing which are provided by the network platform. The course guide is composed of introduction to the course, syllabus, teaching calendar, assessment, teaching environment, and teaching team. The students can know the syllabus, teaching content and experimental environment of the whole course. The classroom teaching includes teaching PPT, emphasis and difficulty, Teaching objectives, experimental instructions and operating video etc. The online testing is composed of my test questions, test item bank, my self-testing and statistic students' exercise. Through online testing, teachers can choose a number of simple subjective questions for students to practice according to the teaching content from the test item bank before the classroom teaching and the teachers can know students' mastery degree to teaching content according to the students' answering to the questions; The teachers can choose a number of difficult questions to further understand the students' mastery degree to emphasis and difficulty after class. Nethomework includes course homework, students' results and forum chatting. The teachers may give the achievement according to homework and results. The teachers can release knowledge related to course and broaden the knowledge of students. Students can also put forward some questions in the forum, teachers answer the questions.

\section{B. Offline learning}

Offline learning includes speak times in classroom, the enthusiasm for participation in group discussion, the completion of experiments and attendance. It can find the students' enthusiasm for the course and the activity of learning and can collect some information that other evaluation methods can't collect through observing attendance, classroom performance. The information can help teachers to adjust the teaching strategy in time. Classroom speaking mainly refers to answer the questions raised by teachers. The questions may be some key issues. The students can use electronic equipment to find answers by the network and summarize the answer. It not only improves the students' ability to summary, but also increases the students' understanding of knowledge. Group discussion is to discuss a project, to express their views, and to put forward different views; the experiments are completed under the guidance of experimental instructions to improve students' practical ability, and to promote students' interesting in learning theoretical knowledge.

\section{Summative Evaluation}

The summative evaluation includes the final examination and the mid-term examination. The mid-term examination and final examination take the form of a closed book. The proportion of the mid-term and final examinations can be adjusted according to the actual teaching situation.

\section{APPLICATION OF THE EXAMINATION MODE}

In this paper, the effect is analyzed from the experimental Classes and non-experimental classes. The experimental Classes use the blending teaching method, the examination method uses the equal.1 to compute. The non-experimental classes use the traditional methods of teaching and use the equal. 2 to compute the examination scores. The test results are shown in Fig. 2 and Fig. 3. Table 1 is the result of the analysis of examination scores.

The Examination Scores of Experimental Class $=$ mid-term examination $* 15 \%+$ final examination $* 20 \%+$ usual performance $* 10 \%+$ course homework scores $* 30 \%+$ using network platform* $25 \%$

The Examination Scores of non-experimental Class $=$ midterm examination $* 20 \%+$ final examination $* 40 \%+$ usual performance $* 10 \%+$ course homework scores $* 30$

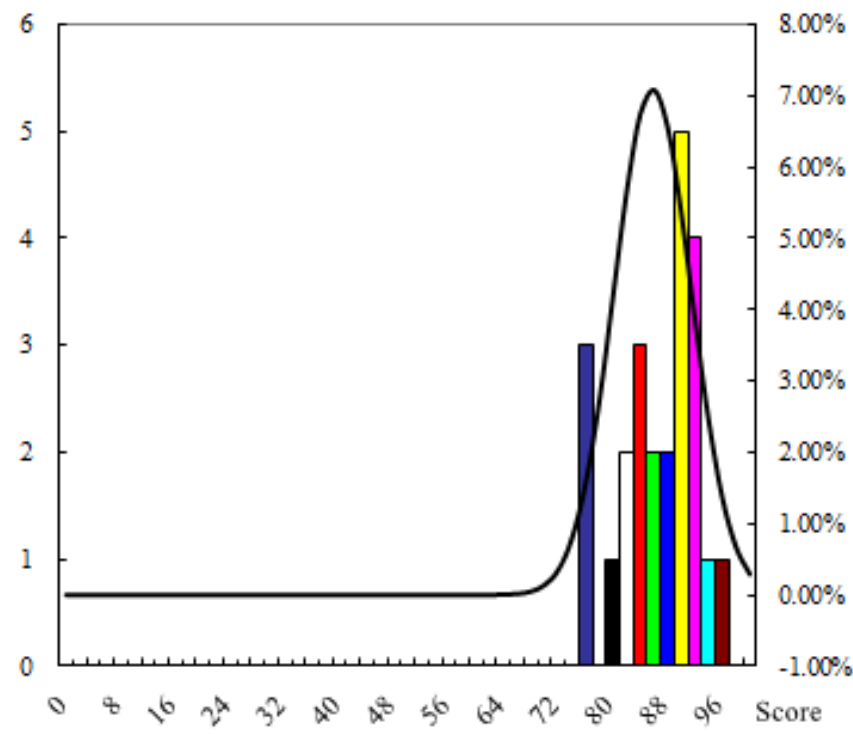

Fig. 2. The Examination Scores of Experimental Class Diagram 


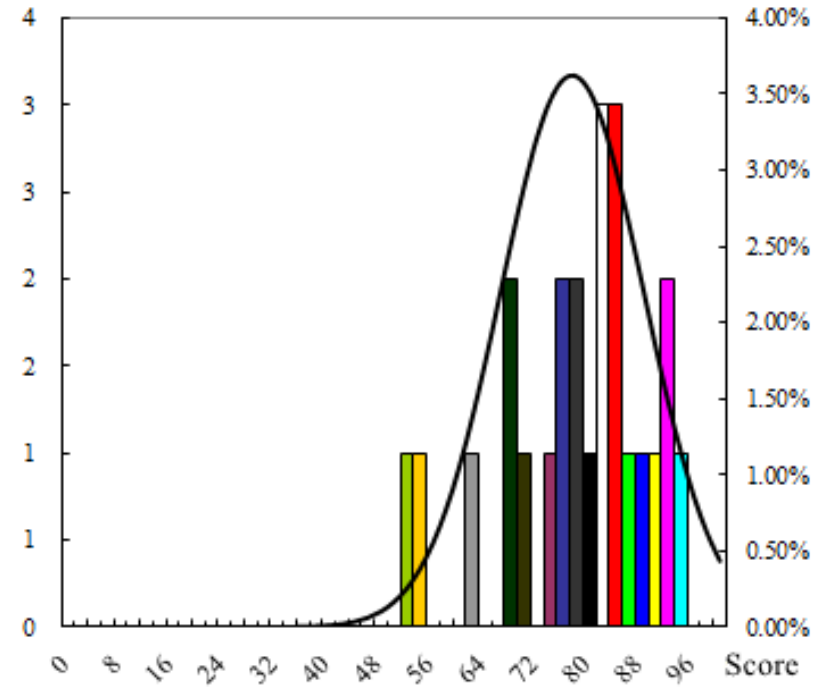

Fig. 3. The Examination Scores of non-experimental Class Diagram

TABLE I. THE ANALYSIS OF EXAMINATION SCORES OF EXPERIMENTAL CLASS AND NON-EXPERIMENTAL CLASS

\begin{tabular}{|c|c|c|c|c|c|c|c|}
\hline Classes & $\begin{array}{c}\text { average } \\
\text { score }\end{array}$ & \multicolumn{4}{|c|}{$\begin{array}{c}\text { different } \\
\text { results }\end{array}$} & \multicolumn{1}{c|}{$\begin{array}{c}\text { pass } \\
\text { rate }\end{array}$} & $\begin{array}{l}\text { Excellence } \\
\text { rate }\end{array}$ \\
\hline $\begin{array}{c}\text { Experimental } \\
\text { Class }\end{array}$ & 85.8 & 7 & 14 & 3 & 0 & $100 \%$ & $30 \%$ \\
\hline $\begin{array}{c}\text { non- } \\
\text { experimental } \\
\text { Class }\end{array}$ & 77.3 & 3 & 10 & 5 & 4 & $92 \%$ & $12.5 \%$ \\
\hline
\end{tabular}

From the final examination results and the analysis table can be seen, the results of the pilot class is better than non-pilot class in pass rate and excellent rate. In the pilot class, the students' comprehensive performance can be emphasized, and the theoretical test scores are emphasized in the nonexperimental class.

\section{CONCLUSION}

The paper discusses the examination mode of combining formative assessment with final examination based on the national learning resources repository on computing application technology. The mode overcomes the shortcomings of traditional classroom teaching that focuses on the final examination results. The teaching practice proves that the examination mode is very suitable for the computer specialized courses, which can stimulate the students' 'interesting in learning and can improve the students' ability to analyze the problems.

\section{ACKNOWLEDGMENT}

This work is supported by grants from Beijing Municipal Education Commission 2015annual Beijing Colleges and Universities Education and Teaching Reform fund project (No. 2015-ms212)

\section{REFERENCES}

[1] D. Shujuan, "Discussion on Development of Blending Teaching in Higher Vocational Institute," Education and Vocation", vol. 14, pp. 8384, 2011. (In Chinese)

[2] H. kehang, "New Development of Educational Technology from the Viewpoint of Blending Learning," E-Education Research, vol. 3, pp. 1-6, 2004. (In Chinese)

[3] B. Ying, Z. HongShun, "Application Research of Blending Learning Theory in Power Electronics and Frequency Conversion Technology Course," Mechanical Vocational Education, vol. 11, pp. 41-43, 2013.

[4] Y. Xiaodong, "The Research of Blended Learning for Computer Basic Course on Moodle Platform", Shandong Normal University Master Degree Thesis, 2010. (In Chinese)

[5] X. YouShan, Z. ZuLin, "Factors Influencing Blended Teaching Quality at Higher Education Institutions", Distance Education in China, vol. 9, pp. 9-14,2012.(In Chinese)

[6] Z. Wu, H. Dan, "Design Multidimensional Structure of Teaching Evaluation in Chinese Education Teaching Forum, vol.43, pp. 208209,2016.(In Chinese) 